\title{
SITUACIÓN DE LA NARRATIVA ARGELINA
}

\author{
por \\ MARCELINO VILLEGAS
}

Es poco frecuente la oportunidad de asistir al nacimiento de una empresa cultural que se dirige e interesa a toda una nación; la narrativa árabe argelina es una de esas oportunidades. No la única ni la primera dentro de las letras árabes de este siglo (1), pero sí la más clara, pues junto con los impulsos individuales y espontáneos concurren en ella rasgos de deliberación completamente nuevos.

Los organismos oficiales proporcionan un espacio de edición y difusión que en principio (2) elimina la incertidumbre de dónde publicar y para quién y cómo, permitiendo a los escritores centrarse en los problemas de expresión. La idea es facilitar una base material que aliente a escribir ficción a cualquiera que esté formalmente capacitado para hacerlo. Las minúsculas ediciones a cargo del autor, el desarrollo vocacional de la obra literaria al margen de otro oficio, a lo máximo las colaboraciones en revistas interárabes de buena difusión, rasgos que marcan (junto con las discusiones entre amigos, la oposición al poder y el entusiasmo por lo nuevol las etapas de esbozo y afirmación de la narrativa iraquil, se transforman en el caso de la argelina en trabajos fijos en diarios, semanarios, revistas especializadas y radiodifusión (3). en holgadas primeras ediciones y rápidas reedicionẹs a cargo de una editora nacional cuya producción se distribuye por todo el país (4).

1) En el caso de la narrativa egipcia y la iraquí también se dieron esas característica. La historia de las tres puede medirse en términos de vida humana (Tawfíq al-Hakim tenía alrededor de ocho años cuando se publicó el Hadit cisa ibn Hišm; Nấ̆b Mahfüz nació cinco anos más tardel, dato que exalta y estimula al observador. Estímulo y exaltación se extreman cuando los 80 años de narrativa egipcia y los 65 de narrativa iraquí se reducen a 30 o, como mucho fluego verernos por quél, a 50 en la narrativa argefina.

12) Año tras año se renuevan las críticas respecto a la gestión de la editora-distribuidora nacional las-Šarika l-wataniyya li-nnaš wa t-tawzrc hasta 1983 , al-Mucassasa l-watanjyya lj-l-kităb desde entonces; la primera se encargaba tambien de la comercialización de materiales escolares y de escritoriol. Cfr. "Algèrie-actualité, 14/20 de diciembre de 1978, p. 14; $2 / 8$ de julio de 1981, pp. 14-15; 14/20 de mayo de 1985, p. 37. "Está lejos dé ser domocráctica, es rigida y se basa enteramente en criterios de rechazon, resume Muhammad Amīn az-Záwi en el número del $1 / 7$ de mayo de 1986 del mismo semanario.

(3) Ahmạd Munawwar, al-Bahī Fuḍalá' y Muṭammad Sạlị̣ Harz Allāh llevan programas semanales en la radio nacional. Por

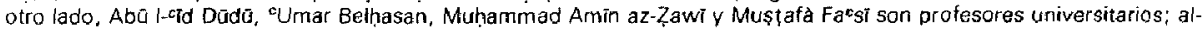
Habib as-Săaị lo es de instituto.

(4) A veces se dan retrasos incomprensibles en la impresión y distribución. al-Janażr, novela de cAbd al-Malik Murtád con permiso de edición de 1982, ha salido a la calle en 1986. Băha s-Şubh de "Abd ai-Hamd ibn Hadũqa, impresa en 1980 , se distribuyó en Orán en 1983 
Funciona tácitamente una escuela de formación de escritores, que se inicia con los ejercicios de aficionado y avanza gradualmente hasta la profesionalización, o sea, hasta la publicación en forma de libro de los trabajos más conseguidos del proceso.

El espacio que aglutina los primeros tanteos es la emisión semanal Adab al-huwāt(5). En cada programa se radia un relato (o más raramente una poesía) seguido de un comentario que se centra en las observaciones gramaticales y en la evaluación de la coherencia formal (6). Después viene la publicación en las páginas literarias de alguno de los cuatro diarios en árabe del país (uašs-Sacb" y aal-Masā'» de Argel, "alYumhüriyya» de Orán y uan-Nașr» de Constantinal. Son las páginas literarias de "al-Ŷmhüriyya», que se publican desde 1977, las que tienen mayor empuje y continuidad (7). Los relatos publicados son objeto de una crítica como mínimo en el mismo diario o en otros medios, y no son raras las polémicas en torno a ellos. Los no publicados reciben a su vez una sucinta valoración, lo cual supone que el título y el nombre de su autor aparecen en letras de molde.

Los escritores que publican en los semanarios ("Adwā'", "al-Muŷāhid al-usbu $\left.\bar{c}^{(} \bar{i} »\right)$ y en las revistas especializadas («Amāil», "aț-Taqăfa») pueden considerarse profesionales en un doble sentido: 1) La continuidad pública de su obra está garantizada, y 2) Se abre ante ellos la posibilidad de vivir de la literatura.

Queda el último paso, que es el libro. Los volúmenes de cuentos primerizos suelen ser poco extensos (entre 70 y 110 páginas) y tienen una tirada de 2.000 a 4.000 ejemplares. Las ediciones de esta clase que se ponen anualmente en la calle son unas diez. 'Abd al-Hamid Bū Rāyū, 'Allāl 'Utmān, 'Ammār Yazli, Muhammad Dahū, Musțafà Națür son, entre otros, escritores que ahora están en ese punto.

Puede ocurrir que se publiquen primeras novelas extensas; al-Mựțahadūn (1985), de al-Hāśsmi Sacdāni, tiene 370 páginas. La bibliografía de la novela árabe argelina se aproxima a los 50 títulos y entre ellos no son raros los que sobrepasan esa medida (8). Aún va a la zaga del cuento, pero su ritmo de crecimiento es muy rápido.

Todas las funciones a que acabo de referirme las asumió en un principio la revista "Ámāl», fundada en 1969 por Mālik Haddād (1927-1978) (9). Los premios literarios no tienen mayor resonancia que la que supone una nota al principio o al final de un texto indicando que ha sido ganador de alguno. Las funciones que en otros lugares desempeñan (descubrir nuevos valores, apoyar comercialmente una obra) están ventajosamente cubiertas en Argelia por otros medios.

Junto al proceso tácito de formación de nuevos escritores hay que mencionar tres proyectos que están o que deberían estar en marcha. El primero es la traducción de obras importantes escritas en francés por argelinos. El segundo, la difusión de la narrativa escrita en árabe durante la época colonial y la guerra de independencia (10). El tercero es el acercamiento al público de los autores posteriores ya consagrados o en vías de afirmación, y la creación de un fondo común expresivo que pueda ser llamado narrativa argelina.

(5) Se radia los martes a las $\$ 7.15$ y dura de 20 a 40 minutos. Suele repetirse otro día de madrugada. Ahmad ibn Diyáb há sido su aditor durante sus tres primeros años de vida, función que pasó a ser desempeñada por al-Acray Wasiñ desde el 1 de abril de 1986.

(6) al-Acrầ Wassini presta mayor atención al estilo y al planteamiento; Ahmad ibn Diyăb lo prestaba a los aspectos gramaticales.

(7) aan-Nadi i-adabī, dirigiđo por Bulqãsim ibn 'Abd Allăh

(8) al Tamoh (1978), de 'Arcar Muhammad al-cĀli, tiene 424 páginas; al-cullayqà (1984), de al-Bahĩ Fudalac, 456

19) Poeta y narrador. Sus cuatro novelas cortas, La derniere impression (1957), Je t'offrirai une gazelle (1958), L'élève et la leson 11960 y le quai aux Heurs ne répond plus 11961 l son brillantes, pero soportan mal la relectura. De Mẫjik Haddád es la frase: "El francés es mi exitio".

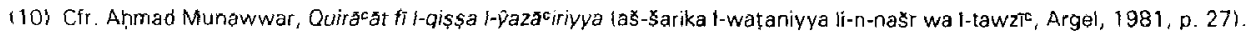


Sobre el primer proyecto cabe decir que es más un desiderátum que un hecho. Mucho más activa es la traducción al francés de las novelas en árabe publicadas a partir de la independencia, que en ciertos casos han logrado a velocidad sorprendente el estatuto de clásicas (11). También es más activa la edición de obras escritas actualmente en francés por autores argelinos; la proporción en que se hace es aún de uno a dos por respecto a las escritas en árabe (12).

$Y$ sin embargo las novelas publicadas entre 1950 y 1970 por Muhammad Dib, Kātib Yāsin, Asiyā Yabbār, Mūlūd Mưaammari, Mūlūd Farawn (13) y otros tendrian que tomar cuanto antes forma árabe si deben participar en la futura cultura argelina. Es un hecho esencial, enmascarado por otros circunstanciales (14), que los planes de estudios puestos en marcha a partir de 1975 desalojan el francés como idioma de expresión concurrente con el árabe (15). Las nuevas generaciones de argelinos no viven el francés como idioma propio y están en camino de no vivirlo ni como idioma próximo; a lo más como un eco confuso del pasado, o como llamada más confusa aún de lo ajeno.

Desde esta perspectiva es natural que la traducción del árabe al francés tenga preferencia sobre la inversa. Esa actividad de traducción es una manera de informar a quienes no pueden o no quieren leer en árabe de cómo ven, expresan e interpretan la realidad del país quienes desde el principio la han vivido en árabe. Y aquí informar es una manera de invitar a la participación.

Esta política de traducción sugiere asimismo que a las obras escritas en francés por argelinos, y aun con tema argelino, se las juzga tan extranjeras como a cualesquiera otras; también que lo que en ellas hay de argelino se tiene por incorporado de otra manera a la actualidad del país. Y, en consecuencia, que la tradición narrativa argelina puede construirse al margen de ellas, y que por estar escritas en árabe son menos extranjeras las novelas y cuentos egipcios, sirios, iraquies, libaneses, tunecinos, etc., que abundan en las librerías del país.

Por otra parte, las que de entre esas obras son inseparables del espíritu de rebelión contra la colonia o las que con mayor precisión fijaron tipos y costumbres, ya habían sido traducidas en otros países árabes cuando en Argelia era aún demasiado pronto para pensar en hacerlo; o siquiera para plantearse si debieran ser traducidas o no.

Si para los escritores y lectores orientales se trata de obras plenamente vigentes, propias y significativas, es porque las leen como mensajes de afirmación árabe y porque saben que la relación con la obra es para ellos el modo más directo de apropiarse y asimilar las realidades de que la obra es expresión y testimonio 1161 .

$111)$ La traducción de las cuatro novelas de cAbd al-Hamīd ibn Hadüqa y de las dos primeras de aț-Ṭahir Wațțår se editó casi simultáneamente a la versión árabe.

(12) En los dos últimos años se advierte la tendencia a que no sean obras de pura ficción, sino testimonios, análisis y memorias noveladas acerca de la elapa colonial y guerra de independencia.

(13) La transcripción francesa con que normaimente se conocen fos nombre se estos escritores es la siguiente: Mohamed Dib, Kateb Yacine, Assia Djebbar, Mouloud Mammeri y Mouloud Feraoun.

114) Que un lercio de la programación televisiva se emita en francés; que el diario y el semanario de mayor circulación se escriban en francés; que en el habla árabe argelina se siga utilizando una cantidad relativamente elevada de palabras francesas arabizadas (si son verbòs se conjugan con morfemas árabes de persona y las transformaciones. Ionéticas han creado palabras virtualmente nuevas, de las cuales el término francés debe considerarse pura y simplemente como el étimo); que en ciertas oficinas estatales aún sea el francés idiorna único; que una parte importante de los intelectuates mayores de 30 años siga prefiriendo emplear el francés como idioma de cultura.

(15) Desde el curso 1981/82, el francés se estudia como idioma extranjero y un año más tarde que en planes anteriores len cuarto de básica). Antes de esa fecha, se impartían en francés materias como matemáticas, física, ciencias... Por otra parte, el inglés se perfila como idioma extranjero alternativo (a partir de este curso $1985 / 86$ ha pasado de idioma opcio$\mathrm{nal}$, en competencia con el alemán y el español, a obligatorio; a partir de octavor.

(16) "Obras que historian el hervor de éste o aquel pais áabe, las novęlas de Gassãn Kanafãnt y de varios narradores de la 
Tomemos el caso de Muhammad Dib: toda su obra ha sido traducida o al menos seguida con atención en Oriente, de La grande maison (1952) a Habel (1977), pasando por Qui se souvient de la mer (1962) (17). Su Trilogía es ventajosamente comparada con la de Naŷib Mahfüz (1956-1957) (18) y como obra árabe se cita al tratar de temas específicamente árabes. $Y$. prueba definitiva de la identificación y la simpatía con que se ha leído: la influencia de uno de los mejores momentos de $L$ 'incendie brilla en al-Qamar wa l-aswār (1977), de 'Abd ar-Rahmān Maŷ̄id ar-Rubaȳī (19).

Pero también puede verse de otra forma: instalado en Francia, escribiendo aún en francés y para una editorial francesa, Argelia ya no es mucho más que un dato mediato en la obra de Munammad Dib. Y si puede decirse que su estética y su visión del mundo son argelinas, no puede afirmarse otro tanto de las obras que produce, del mismo modo que aunque todo el mundo acepta que el estilo de Luis Buñuel era muy español, nadie mantiene que sus películas fueren, salvo raras y dificultosas excepciones, españolas.

La misma dualidad que en Muhammad Dib, pero en otro sentido, se advierte en la obra de Kātib Yāsin: su primera novela es inseparable de la preparación y desarrollo de la guerra de independencia: comenta la represión de 1945 y se dirige a quienes viven en 1956. Su inserción en la realidad del momento y la proyección de futuro de su mensaje, emblemática, queda corroborada por un hecho anecdótico pero significativo: hay argelinas nacidas entre 1956 y 1962 que se llaman Naŷma porque Kătib Yāsin escribió una novela que se llama Nedjma (20) y porque llevar ese nombre era como llamarse Argelia independiente (21).

Después de 1962 publica en francés una nueva aproximación al mundo de Nedima, Le polygone étoilé (1966) y una obra de teatro variada, espectacular y estupendamente esperpéntica, L'homme aux sandales de caoutchouc (1970), impulsada por los grandes temas de la lucha antimperialista y sólo incidentalmente relacionada con Argelia (22).

Más tarde opta por traducirse a sí mismo. Así produce cinco piezas, representadas pero no publicadas, escritas en árabe argelino. Opta también por circunscribir

generación posterior (...) por respecto a la revolución palestina; Le quai aux fleurs ne répond plus y L'élève et la lesson de Mālik Haddadd; las novelas de Muhammad Dib, y la Trilogla en particular; Nedjma, Les ancêtres redoubient sa ferocité

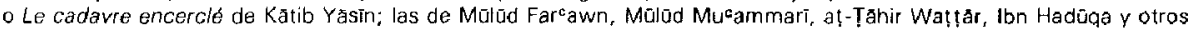
escritores que se expresen en árabe por respecto a la revolución argelina; o las que se refieren a la revolución egipcia de 1952 o a las dos iraquíes de 1958 y 1968 " (...) "Las obras v escritores argelinos tuvieron un importante papef durante la guerra de independencia, haciendo oír la voz del puebio argelino. Extraordinarios documentos que ganaron para nues. tras filas a muchos progresistas de toda el mundo y presentaron nuestra problématica en su marco real, complementando la lucha armada en el logro de la revolución que es un modelo histórico para todos los árabes". "Abd ar-Rahman

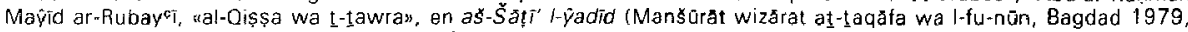
pp. 28 y 311 . Se trata del texto de una conferencia pronunciada en febrero de 1976.

(17) La grande maison forma Trilogía con Lincendie (1954) y Le métièr à tisser (1957); fueron traducidos por Sāmĩ ad Darūbĩ

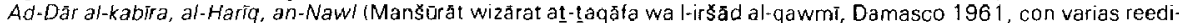
ciones posteriores). Ef mismo año y por el mismo editor se publicó Un été africain (Sayf ifrīi) (1959), traducida oor Ŷürý Sâlim. Antes se habian traducido los cuentos titulados Au café (1955). Fi -maqhả (Beirut, 1959, con varias reediciones posteriores). Habel (1977) ha sido traducida por Muhammad Amin az-7awĩ y publicada en Siria en 1986 . Sobre Oui se souvient de la mer cfr. el artículo de Sa`d Alläh Wannūs, en "al-Macrifa», octubre de 1964, 0.153.

(18) Una muestra en Aḥmad Dọăn, «Awråq min Dimašqu, en "al-Ŷumhūriyyan (Orán). 14 de abril de 1986.

419) En los dos casos se trata de las primeras experiencias sexuales del protagonista. Cfr. L'incendie (Seuil, París, 1954 pp. 112/1171, al-Oamar wa l-aswär lad-Dãr al-carabiyya li-l-kităb, Túnez-Libia, 1982, pp. 121/123 y 129/1331

(20) La traducción española de esta novela ha pasado sin pena ni gloria (Planeta, Barcelona, 19761. Las cuatro primeras novelas de Muhammad Díb se hon traducido y publicado en Cuba.

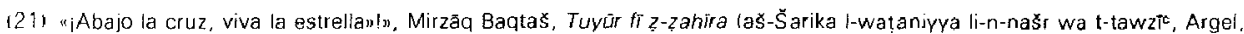
1981, p. 551. La novela evoca el otoño de 1957, en Argel.

1221 El enrolamiento torzoso de argelinos en el ejército colonial francés, tema que episódica pero insistentemente aparece

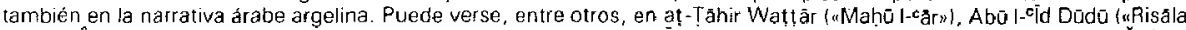

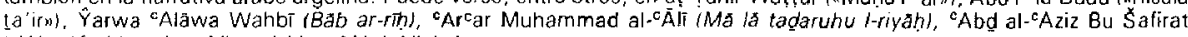
taWuqưf al-bațal», "Aštát dảkirat "Abd Allăhn\}. 
su público: se instala no sólo en Argelia, sino en una ciudad de provincias (Sidi BelAbbés, a 70 kilómetros de Orán y 100 de la frontera marroquí). Estas cinco piezas se representan no sólo en el teatro, también en fábricas y otros espacios reales. A Kātib Yäsin se le debe asimismo el intento de formar una compañía teatral capaz de modificar las costumbres. Todo de una forma voluntariamente subterránea y básica (23).

En definitiva: en un principio se trataba de necesidad histórica; luego, de elección del mundo a que se quiere pertenecer. Cabe predecir que no habrá "narrativa argelina escrita en francés", sino "escritores franceses de origen argelino", y que a partir de ahora es poco probable que escriban en francés otros argelinos que los hijos de emigrantes que hayan optado por la asimilación.

El segundo provecto parece decididamente en marcha y se centra en un escritor, Ahmad Riḍa Hūhū (1911-1956). Como fundador tiene la triple sugestión de haber viajado en los años 30 y 40 por otros países árabes, de haber escrito una obra variada y de haber sido asesinado durante la guerra de independencia. Su figura goza de esa doble dimensión heroica de la muerte violenta a manos del enemigo y de la vida a contracorriente, verdadero pionero que llevó a cabo una obra bastante extensa en circunstancias adversas $y$ por encima de ellas.

La recuperación de los escritos de Ahmad Ridà Hühü se inició en 1983 con la reedición de un libro de cuentos, Săhibat al-wahi (1954) y una novela corta, Gādat Umm a/-qurà (1947). Quedan pendientes otro libro de cuentos Namādiỳ basariyya (1955), una colección de articulos, Maca himăr al-Hakim (1953), sus trabajos dispersos en revistas y diarios y sus manuscritos inéditos (24).

El proyecto de recuperación de Ahmad Ridà Hūnū tiene una razón que puede llamarse simbólica: afirmar y demostrar que la primera narrativa argelina fue escrita entre 10 y 15 años antes de que se produjera la floración de escritores en francés (25), entre 22 y 27 años antes de la independencia y entre 30 y 35 antes de la publicación de $R \bar{i}$, al-yanūb de Ibn Hadūqa, resultando asi que la narrativa árabe argelina no sería una recién nacida de apenas 30 años (los primeros cuentos de lbn Hadũqa. Wattār y Dūdū son de mediados de los años 501, sino contemporánea de la siria y de las primeras obras considerables de la egipcia (Ṭăhā Husayn, Tawfiq al-Hakim) , Y la iraquí (Dū n-Nūn Ayyūb, 'Abd al-Haqq Fạdili)

La eficacia de este trabajo de recuperación afronta dos dificultades. La primera es el carácter poco local de la obra de Ahmad Ridà Hūhū (la mitad aproximadamente transcurre en Arabia; la otra mitad en lugares indeterminados). La segunda sus planteamientos poco actuales (no es poco decir que su estilo está más cerca de al-Manfalū ți que de Dū n-Nūn Ayyūb). La primera dificultad puede sortearse, porque sus temas siguen vigentes (independencia de la mujer, oportunismo, mimetismol. Que se sor-

231 Otra muestra del interés de los escritores orientales por la literatura argelina en francés: Sacd Allăh Wannūs, Le poudre d'intelligence, en "al-Macrifas, febrero de 1968, p. 44.

(24) El primer estudio detallado sobre Ahmad Riḍa Hūnu lo hizo ${ }^{\circ}$ Abod Allāh Rakibĩ en al-Oișșa l-yazsciriyya al-qașira (1968) iad-Dar al-carabiyya ii-l-kitab. Túnez-Libia, 1977, 2. ed.l, espec. pp. 45/49, 74/86, 102/111, $126 / 129$ y $176 / 178$ Ahmad Munawwar le ha dedicado tres artículos en Quirăát fi l-qisșal-yazáciriyya, pp. 23/41, además de los prólogos de las dos reediciones. Cfr. asimismo: "Abd al-Mạlik Murtăd, "Hawla t-turāt al-adabi li-Ahmad Ridá Hūhū", en "ạl-Aqlâm».

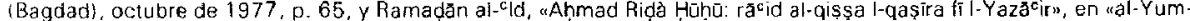
hưrivya” (Oránı, 29 de marzo de 1982. Muhammad Zatīi (1952) se ha puesto a la sombra de Aḅmad Rid̆a Hūhụ al al escribir una serie de artículos titulada Maca himár al-Hakim (1984/85)

(25) Le fils du pauvre, de Mülüd Farcawn se publicó en 1950 . Tanto ésta como sus dos novelas posteriores, La larre et le sang (1953) y Les chemins qui montent \{1957). se han traducido al árabe, la última en Argelia y las dos primeras en Francia (por Seuil, su editora original). Mülud Far'awn y Muthammad Düb son los escritores argelinos con mayor número de textos en los libros de lectura escolares. Far awn tanto en árabe como en francés; Díb solo en árabe. El de séptimo de básica inçluye los fragmentos $1,4,5,6,9,14$ y 18 de La grande maison. El fragmento 4 es la extraordinaria escena de la lección de moral. 
tee la segunda depende sólo de un cambio de gusto. Hoy por hoy, sólo dos escritores practican una narrativa homogénea con la suya: Ahmad Munawwar (1945) (26), que la hace social, con ambientes sólidamente trazados, personajes humanos, anécdota firme y tesis en trasparencia; y más aún Ismāīi Gamūqāt (1952) (27), quien como Ridà Hūhū se vuelca en historias de amor románticas (con lo que esta palabra puede significar tanto de apasionamiento y utopismo como de simpleza), muy laxamente ligadas a un propósito de denuncia social y de vicios individuales de visión del mundo; obras de evasión y compensación que aspiran a exaltar con situaciones fuertes y un mecanismo narrativo sin escapes.

De todas formas es pronto para calibrar el efecto de las reediciones de Ahmad Ridà Hūhū y el resultado que obtendrá el intento de convertirle en iniciador de la narrativa argelina. Una baza importante para la pervivencia de su obra es que en ella conviven registros variados. El que mejor concuerda con el gusto actual es el irónico. bien representado por una dialogada ("Udabā' al-maz̧har») y un cuento "Fatāt ah/āmì) (28); sus cuadros de costumbres, sin embargo, carecen de carácter y agudeza, tanto si versan sobre personajes atrayentes ("Tari /-harb»), como si se trata de conglomerados extraños ("al-Fuqarā'", "Șadiqi $\left.s-s \bar{a}^{c} i r\right)$ ( 29 ), porque en uno y otro caso lo único que cuenta es un moralismo convencional. Sus cuentos de crítica social sufren de inverosimilitud, de tratamiento anarrativo y de nimiedad, sin que el estilo terso y elocuente les ayude a mejorar nada. De los tres que tiene, "ŶYarima hamāt" es el más inverosímil; "al-Qubla l-maš'üma» el que más cerca está de ser simplemente un cuento; "Sāhibat al-wahi", el más declamatorio (30). Son sus melodramas ("Jawla») (31), Gādat Umm al-qurà) los que, de otra manera que sus trabajos ironicos, tienen más posibilidades de encontrar lectores e inspirar obras nuevas. Son relatos que están de acuerdo con el gusto actual por las narraciones bien marcadas $y$ con un doble fondo alusivo, contadas de una manera funcional, objetiva y creciente. Tras la primera alarma llos esquemas narrativos y las anécdotas son de sobra conocidos (32) y Riđà Hūhū los emplea sin la menor reserva), tanto "Jawla" como Gādat Umm alqurà se afirman como obras que admiran y mueven, la primera por su primitivismo. la segunda por la eficacia y la sinceridad con que maneja los resortes del melodrama.

¿Con qué otros puntos de referencia cuentan los narradores argelinos de hoy en el momento de ponerse a escribir? Curiosamente, los escritores más hechos y que constituyen una frontera para las tentativas de los nuevos escritores, son la mínima parte de los que durante la guerra de independencia y algo antes se empeñaron en la tarea de dar una imagen narrativa de Argelia. Algunos, como Ahmad ibn 'Ašūr, Muhammad Sālih aș-Sadiq, Fäḍil al-Mas'ūdi o 'Abd al-Maŷid aš-Säfici (33) han desaparecido del campo de las letras, quién sabe si porque eran narradores de circunstancias, que por necesidad o entusiasmo respondieron al provecto de ilustrar y dar la imagen ideal de la guerra de independencia; quién sabe si porque no fueron capa-

\footnotetext{
126) Ha publicado cuentos sueltos en revistas y aș-Şudăc, colección de once relatos que obtuvo el premio nacional de literatura. Lleva la emisión radiofónica semanal Liqa maca adíb.

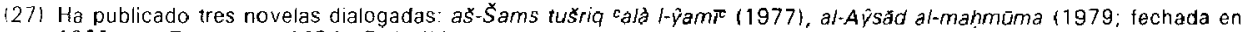
1969 y at-Tahawwur $\{19841$. En fa útima vuelve del revés el esquema romántica y confiado de las dos primeras y presenta un mundo hostil y sin grandeza, oportunista $\gamma$ cinico, donde las relaciones son alianzas circunstanciales, forzadas $\checkmark$ construidas sobre el odio. Junto con a/-Âsád al-mahmüma aparecen cuatro cuentos; el primero de ellos, "as-Sür al ajras yatadacàm, es espléndido.

(28) Sanibat al-wahi, pp. $61 / 75$ y $41 / 49$

(29) id.. pp. $51 / 59,87 / 94$ y $95 / 101$

(30) id., pp. 77/86, 29/40 y $17 / 27$.

(31) id., pp. 101135

432" "Jawla" es un relato de aventuras orientales. Su esquema argumental se encuentra a su vez en numerosas películas del Oeste, y para entonces ya era viejo.

331 Cfr. cAbd Allăh Rakibi, obra citada, espec. pp. 109/132 y 209/228, y at -Tăhir Wattăr, prólogo a Tuyuur fi z*zahira, p. 8
} 
ces de atravesar el desierto que los años 1962 a 1969 fueron para la narrativa árabe argelina (34). Otros, como 'Abd Allāh Rakibi o 'Uțān Sacdi (35) no han desaparecido del campo de las letras, pero sí del de la narrativa.

Quedan cuatro escritores de la generación nacida entre 1925 y 1940 y revelados durante la guerra: 'Abd al-Hamid ibn Hadüqa (1925). Abū l-cld Dūdū (1934), ațTăhir Wattāar (1936) y Zuhūr Wanisi (1936). La última es escritora al margen de su carrera política. Ha publicado tres libros (36): 'Alà $\$$-Săti' 1 -ājar $\left(1974 ; 2\right.$ a $^{\text {ed: }}$ 1979). Min vawmiyyāt mudrarrisa hurra (1979) y az-Zilàl al-mumtadda (1985). Los tres tratan, en palabras del prologuista del último: "del pueblo argelino representado en la revolución y de la sociedad argelina representada en la familia" (37), con un estilo pulcro y algo rígido.

De los otros tres el más igual a sí mismo es Abū l-"đld Dūdū, con cuatro colecciones de cuentos y dos obras de teatro publicadas, además de diversas traducciones (38). Dūdū ambienta bien sus relatos (39), pero carece de fortuna en la selección de las anécdotas - por lo general sosísimas - y embute sus mensajes a la fuerza. Es, en este sentido, un escritor oficial en todo su horror. No obstante, no faltan en sus cuatro libros cuentos donde el estilo, flexible y preciso, consigue interesar y extraer sentido de la relación de un acontecimiento sin relieve pero significativo. "Jayba". de su primer libro, es uno de los mejores ejemplos (40).

Mucho menos iguales a sí mismo son aṭ-Tāhir Wațtār y ${ }^{\mathrm{C} A b d}$ al-Hamid ibn Had ${ }^{-}$ uqa. Watțār lleva bastante tiempo sin publicar nada narrativo (41), desde al-Hawwāt wa /-qașr (Constantina 1980; 2. ${ }^{a}$ ed: Argel 1984), novela cuya primera edición se hizo por cuenta del autor y que en realidad es más antigua (lleva fecha de julio de 1974) que la que publicó inmediatamente antes, 'Urs bigl (Där lbn Ruśd, Beirut 1978), fechada en setiembre de 1975. 'Urs bigl llamó bastante la atención porque analiza los mecanismos de la sociedad burguesa por medio de la vida en un burdel (42). Su tema profundo es el oportunismo; el de al-Hawwāt wa l-qașr es el conformismo, no el individual, sino el de todo un pueblo. Wattār desarrolla su razonamiento paso a paso y de manera exhaustiva, en un marco de fábula. Ambas novelas revelan gran dominio de la palabra y una continua búsqueda de formas significativas, pero resultan monótonas. Al menos en una primera lectura, ingenua y voraz, rebelde a la reflexión.

341 Entre la publicación de Nufüs tăira y la creación de "Āmâlı no hay nuevas producciones narrativas en árabe. Jean Dejeux, La litérature algerienne contemporaine (PUF. Paris, $1975, p .113$ ), se refiere a una novela, La voix de la passion lSawi al-hawa, quizái, de Muhammad Mûni, editada en 1967, de la cual no he visto ninguna otra mención

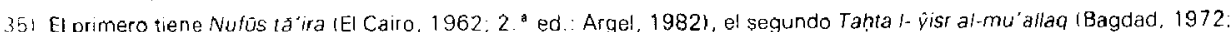
2. ${ }^{a}$ ed: Argel, 1980i. Sadí es autor de una tesis (publicadal sobre cla revolución argelina en la poesia iraquin, tesis que se ha transmitido seriada por Radio Nacional de Argelia.

(36) La tista de obras que incluye su último libro da un título más: ar-Rașif an-nám (El Cairo, 1967), que hașta el momento no se ha reeditado $y$ al que no he visto ninguna otra referencia

(37) cAbd al-Hamid al-Mahrĩ, az-Zilal al-mumtadda, p. 8.

(38) Entre otras la de Amor de don Perlimplin y Belisa en su jardin (Hadiqat al-hubb). Sus obras originales son: Buhavra az-

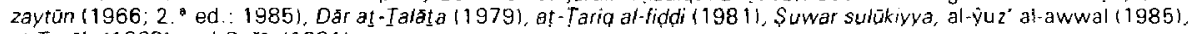
at-Turáb $\{1968)$ y al-Basir 11981$\}$.

391 "Las gotas de lluvia se afanaban en el cristal de la ventanilia del tren, enlazadas ahora, paralelas luego, acosadas por el viento este, asistido en su furor por la velocidad del convoy. Parecian bestezuetas transícidas compitiendo por llegar a una meta ignota. Hasta que por fin se desintegraban en el borde del cristal, hilos de esperanza reducidos a decepción, vacio, violencian, $p .101$ de la $2 .^{a}$ ed. de Buhayrat az-zaytūn.

(40) İd., pp. $33 / 42$.

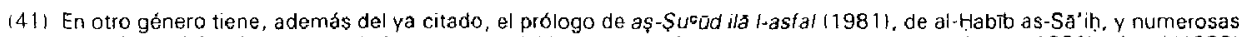
entrevistas. Además, una novela fantasma, al-Hubb wa l-mawt fi zaman al-harasi, impresa en Beirut (1981) y Argel (1982) $\checkmark$ no distribuida en Argelia hasta el momento

(42) Urs bigi no se ha editado nunca en Argelia, pero la edición libanesa se distribuyó y agotó en su momento 
Respuesta más inmediata despiertan las dos primeras novelas de aț-Tāhir Wațār. al-Lãz (1972; 3. ${ }^{a}$ ed: 1978) es abra desmedida, que tras una primera parte sorprendente, intimista, cae en situaciones que quieren ser radicales pero se quedan en delirantes. Su militar homosexual francés no tiene más consistencia que el alemán de Los cuatro jinetes del Apocalipsis de Blasco lbáñez. Y en tal contexto el tema incestuoso queda como expresión efectista de los horrores de la guerra. Al-zilzāl \{1974; 4. ${ }^{a}$ ed: 19801 , cuya forma - circular y estática - coincide felizmente con su propósito y tema, me parece, junto con algunos cuentos, la obra maestra de aț-Tāhir Watțār (43).

El problema de la obra de ${ }^{\mathrm{C}} \mathrm{Abd}$ al-Hamid ibn Hadūqa es su calidad netamente descendente. De la obra maestra que sin duda es Rih al-ŷanūb (1970; 5. ${ }^{a}$ ed: 1986)

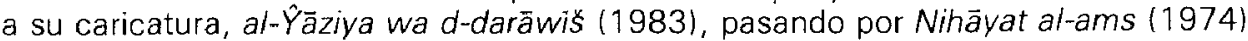
y Bāna ș-șubh (1980), buenas novelas en las que, sin embargo, ya se deja sentir un desagradable amaneramiento en ciertos puntos clave. Que Ibn Hadūqa haya escrito varios cuentos interesantes (44) no disminuye en nada la incertidumbre y el poco crédito que al $\hat{y} \bar{a} z i y a$ wa $d$-darāwis proyecta sobre su obra futura.

La última generación con personalidad definida es la de los narradores nacidos entre 1941 y 1955 , que empiezan a publicar en torno a 1969 y que por término medio tienen entre 3 y 6 libros en la calle. Todos han contribuido ya con algún cuento o novela conseguidos a fundamentar una tradición narrativa árabe argelina.

El defecto común a estos escritores es una preocupación estéril por la técnica, en el sentido de escribir de manera nueva, no tradicional (una preocupación que ya perturbaba Nedjmal, en muchos casos doblada por una gran aridez inventiva $y$ sin la corrección de la escucha atenta a la realidad entorno; casi todas sus obras proporcionan una imagen desdibujada de Argelia, imposible hacerse idea ni imaginar a través de ellas la variedad y vitalidad, las infinitas contradicciones y creaciones. Cuando hay atención aparecen novelas estimables, como Zaman an-Nimrūd, de al-Habīb asSă'ih (1950) (45), donde la busca de una voz propia y de una prosa narrativa con carácter, a la vez exquisita y coloquial, coinciden con una actitud decidida de cara

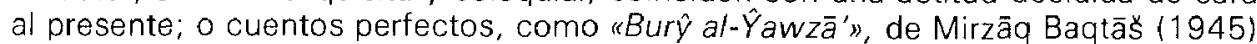
(46), verdadero bofetón a la buena conciencia argelina. De otro modo nos encontramos con novelas como Rā'ihat al-kalb (1985), de Ŷilläli Jalāṣ (1952), que trata de ser iconoclasta con ídolos caídos

El escritor más prestigioso de esta generación es por el momento Rašid Bū $\hat{Y}$ adra (1941) (47). Hasta ahora todas sus obras han sido acogidas con admiración, y $\sin$ haber llegado a crear escuela es manifiesta la influencia de su estilo. La expectación que siempre han despertado sus novelas se ha multiplicado en los últimos años, desde que en 1981 empezó a publicarlas en dos versiones, árabe y francesa, con

\footnotetext{
1431 "al-Tahūna" y "Rumána", pp. $7 / 17$ y $137 / 201$ de la 2. "ed. de at-Tacnắt (Argel, 1976), "az-Zanȳivya wa d-dabit", op. $27 / 60$ de la 2. ${ }^{\circ}$ ed. de aš-Šuhadá yacúduna hada l-ušbū́ (Constantina, 1980). De notar son a su vez dos cuentos esperpénticos de la misma colección: alštirâki hattà l-mawt" (pp. 85/103) y "Zawy̆at aš-săcir" (pp. 105/127). La.primera colección de cuentos de Waltâr Dujăn min qabju (Túnez, 1960; 2. a ed.: Argel. 1982l, tiene un interés simplemente histórico, igual que sus dos obras teatraies.

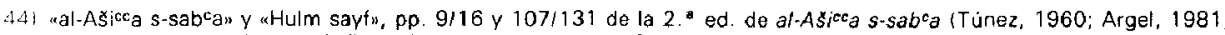
con dos cuentos másl; "al-Kătib", "al-Ugniyya l-qádīma" y "Azizan, melodrama sublime, pero más próximo al cine egipció que a Ridă Hūhū, pp. $5 / 19,97 / 112$ y $113 / 135$ de la $2 .{ }^{\circledR}$ ed. de al-Kătib (Argel, 1977 ).

15) Recién publicada gozó de cierta notoriedad porque una denuncia por difamación forzó a retirarla de las librerias, a las cuales regreso aproximadamente a los tres meses. Un aviso (tanbih) anuncia en la p. 9 que uhechos y personajes son imaginarios, cualquier parecido...", etcétera.

461 Pp. $47 / 66$ de Yarăd al-bah̀r («Amāl”, núm. 45, mayo/junio de 1978). Está fechado el 11 de enero de 1974

147) La transcripción francesa de su nombre, con que normaimente se le conoce, es Rachid Boudjedra.
} 
la mención utraducida del árabe por el autor» en la última; aunque no se trate propiamente de traducción sino de reelaboración (48).

Esto en su séptima y octava, las seis anteriores, editadas en Francia, han sido traducidas al árabe en los últimos cinco años, casi siempre por narradores de su misma generación.

La notoriedad de Rašid Bū Ŷadra arranca de su primera novela, La répudiation (1969) (49), que forma díptico con su segunda, L'insolation (1972) (50). Ambas exponen las fantasias de un individuo a caballo entre dos mundos (francés $y$ argelino: masculino y femenino; paterno y materno $(51))$, de los cuales se evade por medio del delirio calculado. Las dos primeras novelas de Bü $\hat{Y}$ adra tienen serias analogías con las de la última etapa de Juan Goytisolo (52):

- Empleo provocador del tema sexual.

- Construcción fragmentaria.

- Utilización irónica de términos cultos y raros. Coinciden específicamente en dos: mirífico y avuncular.

- Abundancia de referencias intertextuales (estilo científico, periodístico, publicitario, oratorio, coloquial...).

- Descripciones hechas por acumulación de frases sin verbo (53).

Topographie idéale pour une agression caractérisée (1975) (54) trata de las agresiones racistas contra argelinos en Francia. Su escenario son los pasillos y vagones del metro vistos por una mirada sin costumbre. El personaje y conciencia narradora es múltiple: el recién llegado y quienes le vieron. Novela laberíntica de la cual emergen nítidas dos ideas: carácter monstruoso de la sociedad de consumo; absurda fascinación que ejerce sobre quienes no la viven.

En L'escargot entêté (1977) (55) el delirio del personaje se expresa en formas ordenadas, reflexivas y lógicas, con un giro de $180^{\circ}$ de lo que parecía inseparable del escritor. El personaje y narrador de ésta no es un tipo marginal, sino un jefe de negociado que expresa sus locuras con la técnica del informe profesional.

L'escargot entêté manifiesta estar escrita tras una apasionada lectura de Jorge Luis Borges:

(48) Personajes episódicos como ${ }^{\circ} \bar{A}$ iša ia rapida, que aparece como un estrúbillo en Le démantelement 1Denoël, Paris, 1982. pp. 166, 178 y 180 l están ausentes de at-Tafakkuk laš-Sarika l-wațaniyva li-n-našr wa t-tawzī, Argel, 1982, 2." ed., pp. 130, 142 y 144. Temas como la homosexualidad, importantes en at-Tatakkuk (discurso de Latit, pp. $210 / 211$ ) están ausentes en Le démantẻlement $\{\mathrm{p}$. 2471. Situaciones como la masturbación de Sălima/Selma son mucho más detalladas en at-Tatakkuk \{0. 1891 que en Le demantèlement 10. 2271. Aparte de estas diferencias de detalle entre las dos versiones hay diferencias de grado: están escritas dentro de dos literaturas diferentes $v$ el lector no las acogera con las mismas conexiones literarias y referenciales. La mención straducida del áraben significa entonces que su referente y destinatario orimeros son árabes.

449. Todas las novelas ofe Rašía Bū Yadra han sido editadas en francés por Denoèl (París) y en arabe por los dos organismos mencionados en: la nota 2. Por ello, prescindo de indicar las a partir de ahora. De La répudiation hay dos versiones árabes:

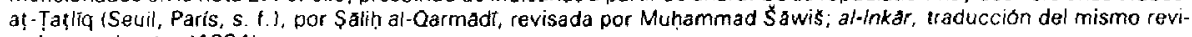
sada por el autor $(1984)$.

(50) ar-Racn (1984), versión del autor

151) En carta de 16 de marzo de 1985 , responde el escritor a mi propuesta de asociación automática: padre/repulsión (kara hiyyal; madre/piel suave (riqqat al-basara).

152) Aesulta tentador pensar que pudieran conocerse en Paris, donde residieron por las mismas fechas.

1531 «Antes ĺbamos a la mezquita con un pañuelo limpio a la cabeza. Palitos de ámbar. Fervor real. Filas de fieles, pero las mujeres detrás de los hombres, al fondo de la mezquita. Esteras. Ricas affombras. Vidrieras. Voz melodiosa del iman. Murmulios. Esplendores: arabescos y vidrieras. Como niños que eramos, siempre admirados por el despliegue de lasto y de iuz. Corán. Estremecidos (¿De miedo? ¿No nos dejaba la salacidad en aquel espacio de fe? ¡Nunca! ¡Nila lascivialln. La répudiation, pp. 22123

(54) ar-irãta (1983), traducción de Yỉilăli Jalăs

(55) airhalazūn al-caníd 11981, 2. ed.: 1985), traducción de Hisăm al-Oarawí. 
«Comprendo a los habitantes de Uqbar - ciudad iraquí- que en el siglo VIl de la héjira organizaron un estado indendiente. Proscribieron de sus vidas los espejos y la copulación porque multiplican el número de hombres" (56).

Y luego la invención de personajes y obras apócrifos: junto al matemático Silas Haslam (57).

La presencia intertextual de Borges en esta novela, y la de García Mázquez en la siguiente, parece atraída por un tema general (antropológico, psicológico, político), la oposición aztecas/españoles (58).

En Les 1001 années de la nostalgie (1979) (59) hay numerosos homenajes y referencias cómplices a. 100 años de soledad; la propia idea de la novela resulta tributaria de ella. Hay asimismo (como lo habrá en su última novela, al-Maraț (60) trato intertextual con Las 1001 noches, en muchos casos no por sí misma, sino en cuanto inspiradora de Borges y García Márquez. Este juego entre tres polos lun escritor árabe es estimulado por una obra clásica árabe a través de un escritor argentino o colombiano) (61) anuncia las reflexiones de Rašid Bū $\hat{\gamma}$ adra, en ésta y las dos novelas siguientes, acerca del corte entre la cultura clásica árabe y la presente.

Les 1001 annés de la nostalgie refiere la peripecia de una familia sin apellido. que le fue robado por un colono al abuelo de Muhammad, el protagonista. Es también la historia del rincón perdido donde viven, Manāma, y de las distintas incidencias que producen en él su sistema de gobierno y relaciones con el exterior. Es cierto que Manāma suena un poco como Macondo, pero más importa lo que significa: es la cama, el dormitorio o el sueño donde yacen todos los manameños, o sea, todos los árabes.

El homenaje más abierto que Rasid Bū Ŷadra tributa a Garcia Márquez en esta novela es la enumeración de los productos que pueden encontrarse en el mercado de contrabando de Manāma, lista que hace eco a la de las atracciones que pueden admirarse en la feria de los gitanos que visitan Macondo:

\footnotetext{
156) La legendaria ciudad iraqui procede de "Tlón, Uqbar, orbis tertius", en Ficciones (1944). Chr. Prosa completa (Bruguera. Barcelona, 1980, 1, 409 y ss. I. "Los espejos y la procreación. de "El tintorero enmascarado Hákim de Merv", en Historia universal de la infamia (1935), id., I, 287. A este relato se remontan las reflexiones sobre los movimientos revolucionariós en el Islam, que abundan en las tres últimas novelas de Rašid Bū Y̧adra

(57) Borges inventó a Haslam en "Tion, Uqbar, orbis tertius", obra citada, 1, 411. Ibn Bahr aparece en las pp. $17,89,93$. $95,98,108,113.131$ y 213 de L'escargot entêté Silas Hasiam en las pp. 19.93, 95 y 98

1581 L'escargot entèté, pp. 138/139, 143, 156/157

(59) Alf cămm wa 'amm min al-hanin 1981; 2. ed : 1984), traducción de Mirză Baqtảs.

4603 Especialmente en las páginas de un guión adaptado de esa obra, pp. 113;135

161) ¿Premonición a anuncio? El cartel publicitario de café de Colombia es uno de los más detatlada y reiteradamente descri. tos en Topographie idéale pour une agression caractérisée.
} 


\begin{tabular}{|l|l|}
\hline RASID BÜ YADRA & GABRIEL GARCIA MAROUEZ \\
\hline "... bebidas prohibidas, revistas porno- & "...con sus loros de todos los colores \\
gráficas, alfileres para abortar, molini- & que recitaban romanzas italianas, y la \\
llos para pulverizar la tristeza, ropa in- & gallina que ponía un centenar de hue- \\
terior escalofriante, preservativos lubri- & vos al son de una pandereta, y el mo- \\
ficados, amuletos lúbricos, recetas & no amaestrado que adivinaba el pen- \\
contra las penas cordiales, vaqueros & samiento, y la máquina múltiple que \\
de Formosa, consoladores mecánicos, & servía para pegar botones y bajar la fie- \\
elixires para crecer, televisores en co- & bre, y el aparato para olvidar los ma- \\
lor, caricaturas del Gobernador, alfom- & los recuerdos, y el emplasto para per- \\
bras mágicas de Samarkanda, esteri- & der el tiempo, y un millar de invencio- \\
lets infalibles, planchas para las arru- & nes más tan ingeniosas e insólitas que \\
gas, máquinas para coser los sietes de & José Arcadio hubiera querido inventar \\
la vida, recipientes para fermentar el & la máquina de la memoria para poder \\
tiempo, cafeteras para hervir el abu- & acordarse de todas" (62). \\
rrimiento, procedimientos para fomen- & \\
tar las conspiraciones, recambios de & \\
Rolls Royce 19, armas utilizadas para & \\
asesinar a los zares de Rusia, guilloti- & \\
nas afiladas de Mahmud II, la espada & \\
de Cid Ali, manuscritos apócrifos y & \\
sospechosos, revistas de modas pasa- & \\
das de mada, aparatos para fastidiar- & \\
se la vida, pildoras para trocar los se- & \\
xos" (62). &
\end{tabular}

Aunque hay otros, igualmente importantes, por lo manifiestos y por la adecuación que adquieren en el discurso de Rašid Bũ Ýadra. Voy a mencionar dos:

- Los gemelos de 100 años de soledad cruzados con los 16 hijos del coronel Aureliano Buendía dan a Muhammad-sin-apellido y sus 16 hermanos gemelos, uno de cada sexo por parto. Raśid Bū Ýadra hiperboliza con verdadera satisfacción la imaginación hiperbólica de García Márquez. La capacidad de dar rienda suelta a la fantasía sin merma del sentido es lo que le ha seducido en él. Sobre una base compartida: el carácter hiperbólico que tanto América como el Mundo Árabe tienen.

- El rodaje de Las 1001 noches que efectúa en Manāma una productora estadounidense es homóloga de la instalación de la compañía bananera en Macondo (63).

Le vainqueur de coupe (1981) (64) me parece escrita en respuesta a L'étranger de Camus, impresión que de momento no trato de fundamentar.

At-Tafakkuk/Le démantélement (1981) (65) es a la vez una historia familiar y una

(62) P. 77. Reiterada en las pp. 298/299. con ciertas variaciones de detalle $y$ disposicion gramatical. $P$. 73 de la edicion de Espasa Calpe (Madrid, 19821. En la trase que subrayo veo una invitación a la que Rasió Bü Yadra ha respondido

1631 Pp. 205/252 de Les 101 annés de la nostalgie; $267: 272$ y 324/350 de la ed. cit. de 100 años de soledad

(64) Darba ỳazá (1984), traducción de Mirzăa Baqtãs.

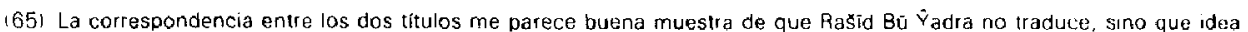
variantes. Traduciendo, creo preferible verter at-Tafakkuk por la escisión. La primera edición de esta novela fue pubicada por Dar Ibn Ruśd (Beirut). 
reflexión sobre los años de independencia. Oscila entre la fragmentación delirante de sus primeras novelas $y$ las reflexiones de distintos personajes que alternativamente toman la palabra. Como la siguiente, al-Marat/La macération (1984), es una summa de su narrativa anterior, a más de proseguir y ampliar la reflexión iniciada en Les 1001 années de la nostalgie sobre norma y desviación en la cultura árabe-islámica y sobre la invención gratuita en la época imperial. Ambas cosas requeririan un estudio detallado; también lo requeriría el tema español en la narrativa argelina. Su amplitud y especialización me aconseja dejarlo para un trabajo independiente.

Orán, noviembre de 1985/mayo de 1986 